\title{
Philosophiques
}

\section{Index du volume I}

Volume 1, numéro 2, octobre 1974

URI : https://id.erudit.org/iderudit/014437ar

DOI : https://doi.org/10.7202/014437ar

Aller au sommaire du numéro

\section{Éditeur(s)}

Société de philosophie du Québec

ISSN

0316-2923 (imprimé)

1492-1391 (numérique)

Découvrir la revue

Citer ce document

(1974). Index du volume I. Philosophiques, 1(2), 178-179.

https://doi.org/10.7202/014437ar

Ce document est protégé par la loi sur le droit d'auteur. L'utilisation des services d'Érudit (y compris la reproduction) est assujettie à sa politique d'utilisation que vous pouvez consulter en ligne.

https://apropos.erudit.org/fr/usagers/politique-dutilisation/
Cet article est diffusé et préservé par Érudit.

Érudit est un consortium interuniversitaire sans but lucratif composé de l’Université de Montréal, l'Université Laval et l'Université du Québec à Montréal. Il a pour mission la promotion et la valorisation de la recherche. https://www.erudit.org/fr/ 


\section{INDEX DU VOLUME I}

1. Articles

N. $1 \quad$ N. 2

ALIARD, Guy $H$. L'énigme et la culture litéraire d'Augustin

GARCEAU, Benoît

Les travaux de jeunesse de Hegel et l'interprétation de sa philosophie de la religion.

GAUTHIER, Yvon Constructivisme et structuralisme dans les fondements des mathématiques.

GUEROULT, Martial Méthode en histoire de la philosophie.

LAGUEUX, Maurice L'arrière-fond philosophique du concept de plan.

MADISON, G. Brent Le postulat d'objectivité dans lla science et la philosophie du sujet. 107

McCORMICK, Peter Heidegger sur le chemin du langage.

PANACCIO, Claude Langage ordinaire et abstrait chez Guillaume d'Occam.

VALCKE, Louis

Le monisme épistémologique de la science contemporaine. 
2. Etudes critiques

AUROUX, Sylvain, L'empirisme de Locke, par F. Duchesneau. $\quad 147$

REBOUL, Olivier La théologie kantienne pré-critique par P. Laberge.

SAUVE, Denis

La cohérence de la doctrine kantienne de la liberté, par B. Carnois.

3. Bulletin

LANDRY, Albert-M. La Pensée philosophique médiévalle.

Contribution canadienne (1960-1973).

4. Interventions

D'HONDT, Jacques Utopie et Liberté.

MORIN, Serge

Sur l'injustice de structure.

5. Chronique 